\title{
Effects of Alpine Wetland Landscapes on Regional Climate on the Zoige Plateau of China
}

\author{
Junhong Bai, ${ }^{1}$ Qiongqiong Lu, ${ }^{1}$ Qingqing Zhao, ${ }^{1}$ Junjing Wang, ${ }^{1}$ and Hua Ouyang ${ }^{2}$ \\ ${ }^{1}$ State Key Laboratory of Water Environment Simulation, School of Environment, Beijing Normal University, Beijing 100875, China \\ ${ }^{2}$ Institute of Geographical Sciences and Natural Resources Research, Chinese Academy of Sciences, Beijing 100101, China \\ Correspondence should be addressed to Junhong Bai; junhongbai@163.com
}

Received 24 July 2013; Revised 2 September 2013; Accepted 1 October 2013

Academic Editor: Xiangzheng Deng

Copyright (c) 2013 Junhong Bai et al. This is an open access article distributed under the Creative Commons Attribution License, which permits unrestricted use, distribution, and reproduction in any medium, provided the original work is properly cited.

\begin{abstract}
The differences in the air temperature, precipitation, evaporation, and relative humidity between wetlands and nonwetlands were analyzed to investigate the effects of alpine wetlands on regional climate. Meanwhile, the changes in precipitation and surface runoff fluxes before and after the typical wetland degradation were discussed, and the effects of wetland degradation on soil organic carbon were assessed. Correlation and regression analyses were applied to exhibit the relationships between wetland landscape areas and meteorological factors. Our results showed that the cooling effects of wetlands on ambient environment were very obvious, and soil temperature could be higher in the area with less surrounding wetland area. The evaporation capacity and relative humidity in wetlands were higher compared to the surrounding non-wetlands. Precipitation and surface runoff flux decreased due to serious wetland degradation, indicating that wetland degradation or expansion had close relation with regional precipitation. Once peat soils were converted to meadow soils or Aeolian sandy soils, soil organic carbon (SOC) would decline linearly. Correlation and regression analyses showed that there were significant correlations between wetland landscape areas and the annual average air temperature, the average air temperature in growing seasons, and the evaporation in growing seasons $(P<0.05)$.
\end{abstract}

\section{Introduction}

Wetlands are the important underlying surface types on the earth and have their own radiation, thermal and hydrous properties, which can form unique microclimate with significant cooling and humidifying effects [1, 2]. Changes in wetland landscape patterns due to varying hydrological processes have profound impacts on wetland biodiversity, ecological processes, and the emission of greenhouse gases as well as regional and even global climate [3], which is closely related to wetland function changes such as carbon accumulation and emission (i.e., $\mathrm{CO}_{2}$ and $\mathrm{CH}_{4}$ ) [4]. Some researchers have presented that wetland drainage (including peatlands) can increase soil respiration $[5,6]$ and have a significant contribution to the feedback processes of carbon cycle and climate change [7]. Therefore, wetlands play an important role in global warming as a result of the great potential of carbon emission [8].

Zoige Plateau is a hummocky plateau with the highest and largest area of alpine peatland wetlands worldwide. The alpine wetlands on the Zoige Plateau cover approximately $470,000 \mathrm{hm}^{2}$, where the amount of reserved peats can reach up to 7.6 billion $\mathrm{m}^{3}$ and become the biggest peat mining area in China. However, these alpine peatlands are suffering from serious degradation or alternation due to global climate change and anthropogenic activities, which have caused a large amount of carbon release [9]. Moreover, the wetland degradation and peat decomposition, in turn, will affect the regional climate change, and thus promoting global warming. Therefore, it is an ideal site for scientists to investigate the relationship between alpine wetlands and global climate change on the Zoige Plateau. Previous researches have focused on the changes in wetland landscape patterns as well as carbon storage and emission [10-12], however, little information is available on the effects of alpine wetland changes on regional climate.

The primary objectives of this study are (1) to investigate the cooling effects of wetlands based on meteorological factors of wetlands and nonwetlands; (2) to analyze the changes in the precipitation and surface runoff flux before 


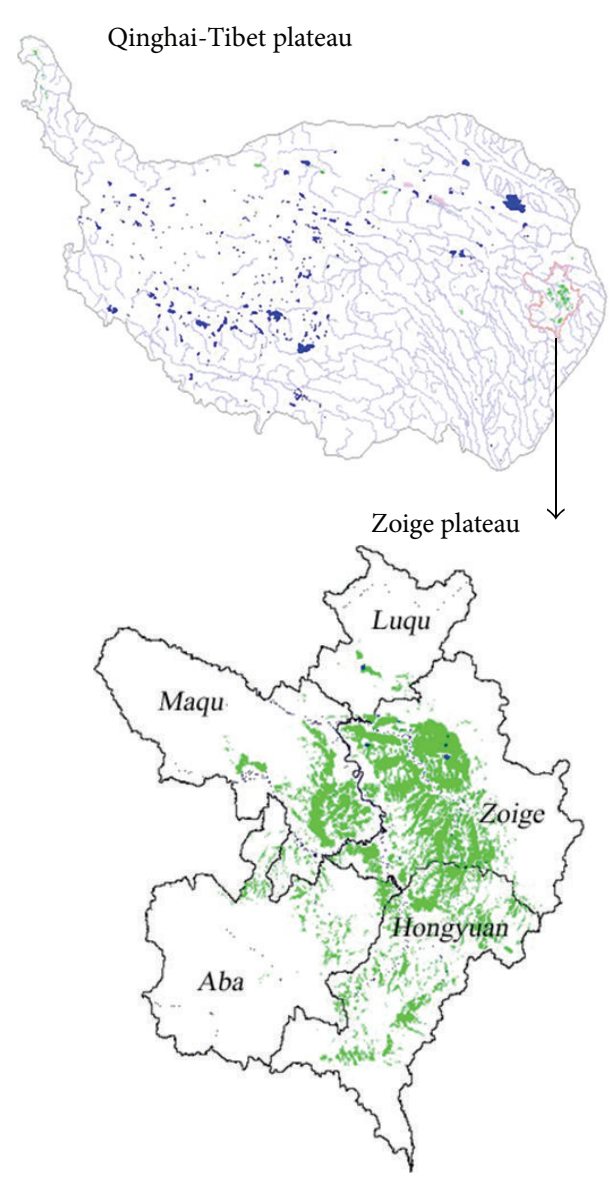

$\square$ Lake
$\square$ River
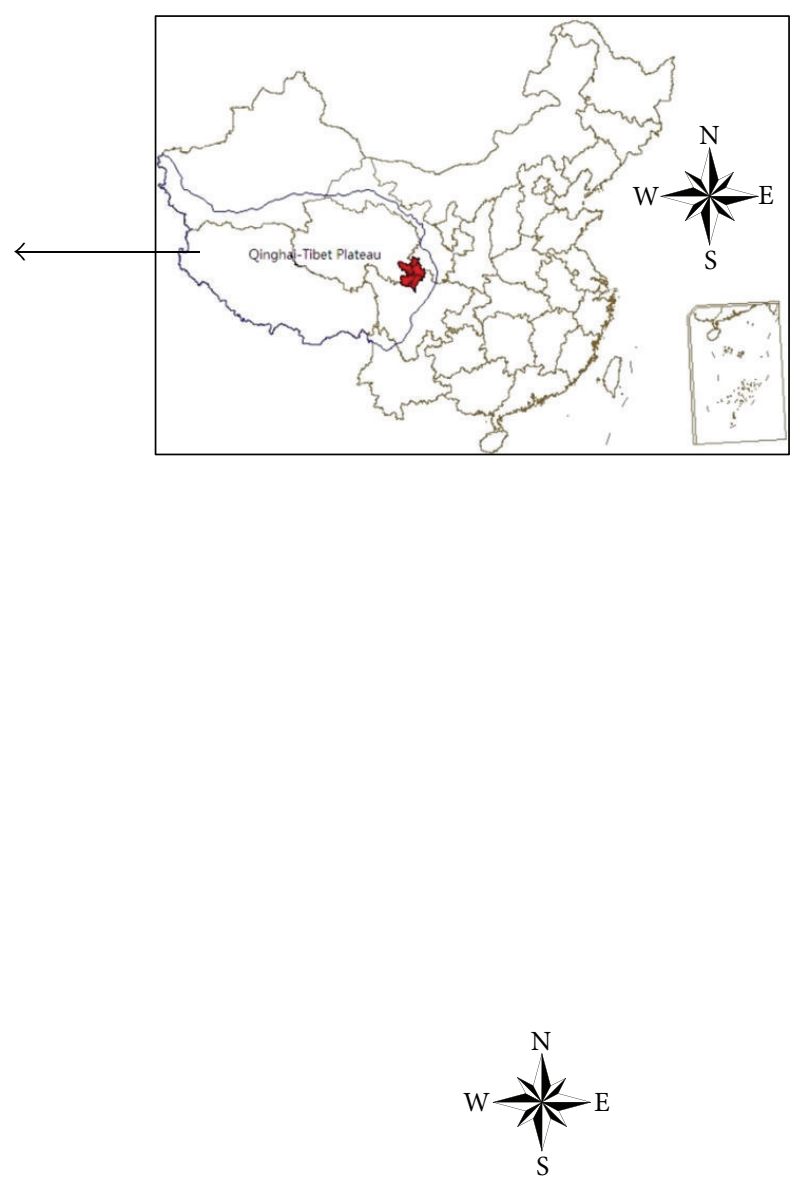

Marsh

Boundary

Figure 1: Location map of Zoige Plateau on the Qinghai-Tibet Plateau.

and after wetland degradation using geographic information system; (3) to reveal the effects of wetland degradation on soil organic carbon; and (4) to identify the relationships between changes in wetland landscape area and meteorological factors using correlation and regression analyses.

\section{Materials and Methods}

2.1. Site Description. Alpine wetlands on the Qinghai-Tibet Plateau are unique wetlands worldwide. The Zoige Plateau, which is located in the northeastern part of the Qinghai-Tibet Plateau (Figure 1), is a dome-shaped geographical unit with large area of alpine peatlands [13]. The Zoige Plateau $\left(33^{\circ} 10^{\prime}\right.$ to $34^{\circ} 06^{\prime} \mathrm{N}, 101^{\circ} 36^{\prime}$ to $103^{\circ} 25^{\prime} \mathrm{E}$ ) administratively belongs to Zoige, Hongyuan, and Aba counties in Sichuan Province as well as Maqu and Luqu counties in Gansu Province $[10,11]$. It is a crucial ecological function area of water conservation with the water storage of about 840 million $\mathrm{m}^{3}$ along the upper reaches of the Yellow River and a significant living habitat for wetland biodiversity conservation. The dominant vegetation types are subalpine meadow and wetland vegetation (i.e., Kobresia tibetica, Muli sedge, and Carex lasiocarpa). This region has a typical humid and semihumid continental monsoon climate of plateau cold temperate zone [11]. It has more rains and heat in the same season, and the air temperature varies significantly from day to night. The annual mean air temperature is $0.6-1.2^{\circ} \mathrm{C}$, with a long frost period. The extreme low and high air temperatures are $-33^{\circ} \mathrm{C}$ and $28^{\circ} \mathrm{C}$, respectively. The annual mean precipitation is $600-$ $800 \mathrm{~mm}$, while the annual evaporation is higher compared to the annual mean precipitation. The rainstorm and hail weather is more frequent, accounting for $90 \%$ of the total annual rainfall in warmer seasons (from May to October). This region has a long sunshine time and sufficient solar radiation.

2.2. Data Sources and Analysis. Five main meteorological stations were chosen in this region. These meteorological data including the monthly average air temperature, the precipitation, the evaporation, and the relative humidity from 1961 to 2000 and soil temperature data from 1961 to 1980 
TABLE 1: Correlation matrix between wetland landscape areas and regional meteorological factors on the Zoige Plateau.

\begin{tabular}{|c|c|c|c|c|c|c|c|c|c|}
\hline & A & AP & PGS & AAAT & AATGS & $\mathrm{AE}$ & GSE & AARH & ARHGS \\
\hline A & 1.000 & & & & & & & & \\
\hline $\mathrm{AP}$ & -0.340 & 1.000 & & & & & & & \\
\hline PGS & -0.266 & $0.749^{* *}$ & 1.000 & & & & & & \\
\hline AAAT & $-0.516^{*}$ & 0.090 & 0.074 & 1.000 & & & & & \\
\hline AATGS & $-0.447^{*}$ & 0.009 & -0.089 & $0.973^{* *}$ & 1.000 & & & & \\
\hline $\mathrm{AE}$ & -0.356 & -0.227 & -0.245 & $0.465^{*}$ & $0.460^{*}$ & 1.000 & & & \\
\hline EGS & $-0.470^{*}$ & -0.306 & -0.313 & 0.568 & 0.568 & 0.641 & 1.000 & & \\
\hline AARH & 0.395 & 0.320 & -0.016 & -0.286 & -0.267 & -0.100 & -0.185 & 1.000 & \\
\hline ARHGS & 0.302 & 0.425 & 0.321 & $-0.512^{*}$ & $-0.554^{*}$ & -0.109 & $-0.622^{*}$ & $0.573^{*}$ & 1.000 \\
\hline
\end{tabular}

${ }^{*}$ Correlation is significant at the 0.05 level (2-tailed).

** Correlation is significant at the 0.01 level (2-tailed).

AP: annual precipitation; PGS: precipitation in growing seasons; AE: annual evaporation; EGS: evaporation in growing seasons; AAAT: annual average air temperature; AATGS: average air temperature in growing seasons; AARH: annual average relative humidity; and GSARH: average relative humidity in growing seasons.

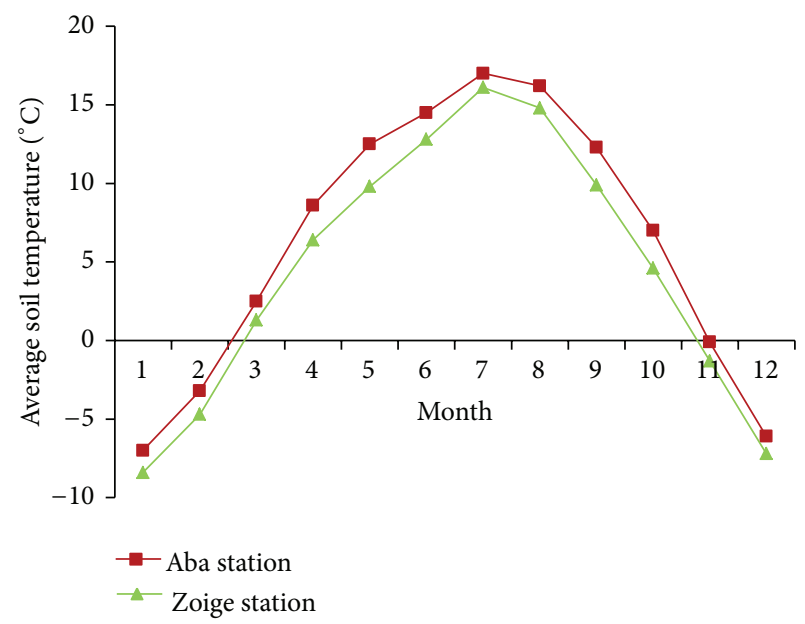

FIGURE 2: Changes in multiyear monthly average soil temperatures at Zoige and Aba stations during the period from 1960 to 1980.

(no longer time series of data) were collected from the above five stations. More detailed information on meteorological stations has been described by Bai [14]. With respect to the short-term monitoring data, we developed a relationship with the similar terrain station and adjacent year length to predict the missing monitoring data. Both Aba (in nonwetland area) and Zoige (in wetland area) stations were selected to compare the average air temperature between them. Land-use data and hydrological data sources in the four years of 1966, 1986, 1995, and 2000 were described in detail by Bai et al. [10]. Meteorological and hydrological grid data of Zoige Plateau were applied to analyze the differences in the air nonwetlands, and the grid data was obtained based on the interpolation of meteorological station data.

Soil samples with five replicates were collected in the three land use types such as peatlands, meadows, and sand dunes. All soil samples were air-dried for three weeks, and all coarse plant debits, roots, and stones were removed. The air-dried soils were ground and sieved through $0.18 \mathrm{~mm}$ mesh sieve for

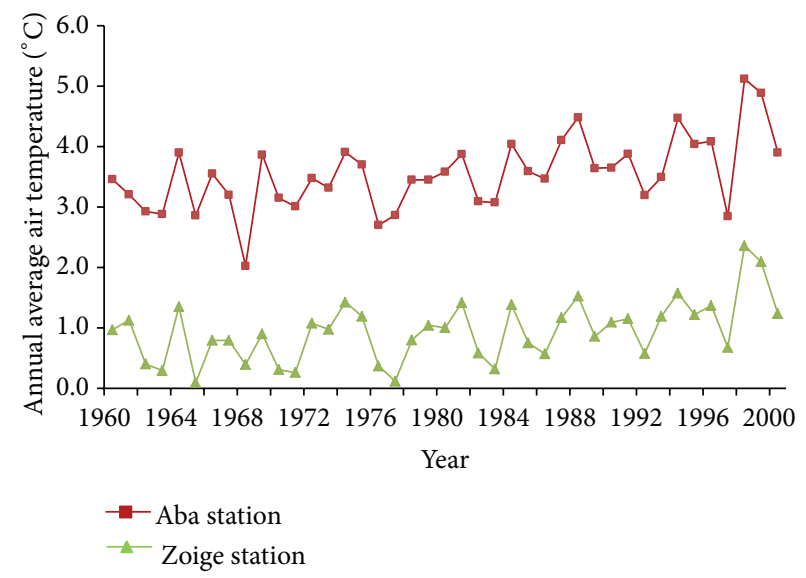

FIGURE 3: Changes in annual average air temperatures at Zoige and Aba stations during the period from 1960 to 2000.

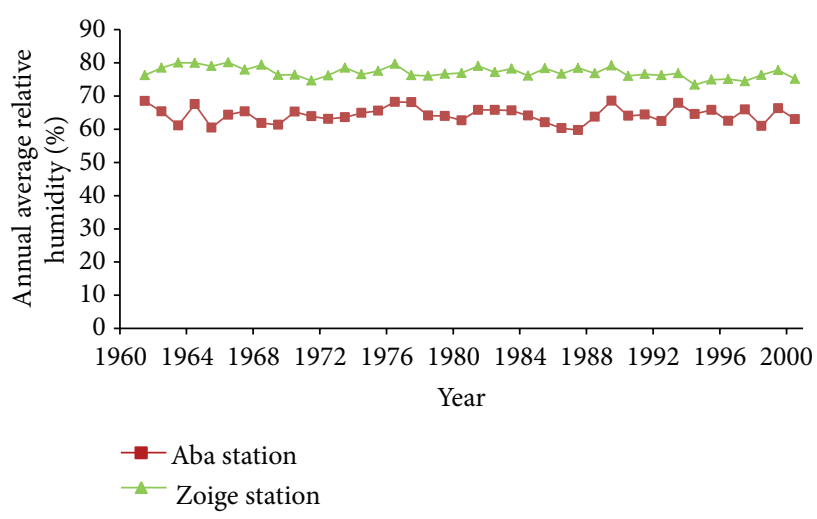

FIGURE 4: Changes in annual average relative humidity at Zoige and Aba stations during the period from 1960 to 2000.

the determination of soil organic carbon (SOC). The SOC was determined by the method of Walkley and Black [15].

Correlation analysis was carried out to identify the relationship between wetland landscape areas and meteorological factors. Statistical analysis was performed using 

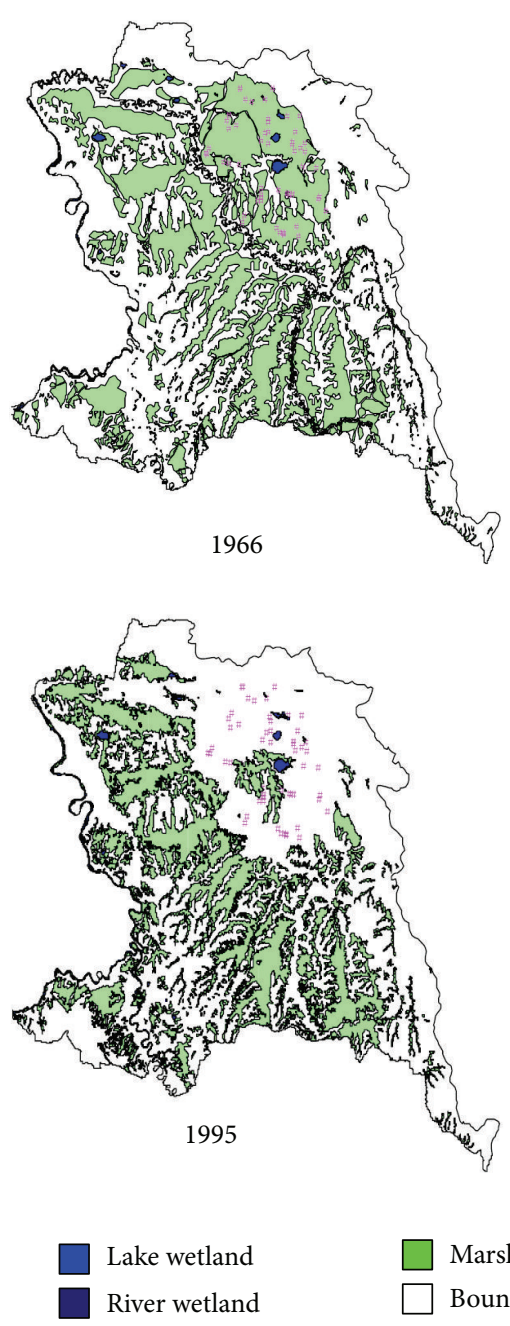
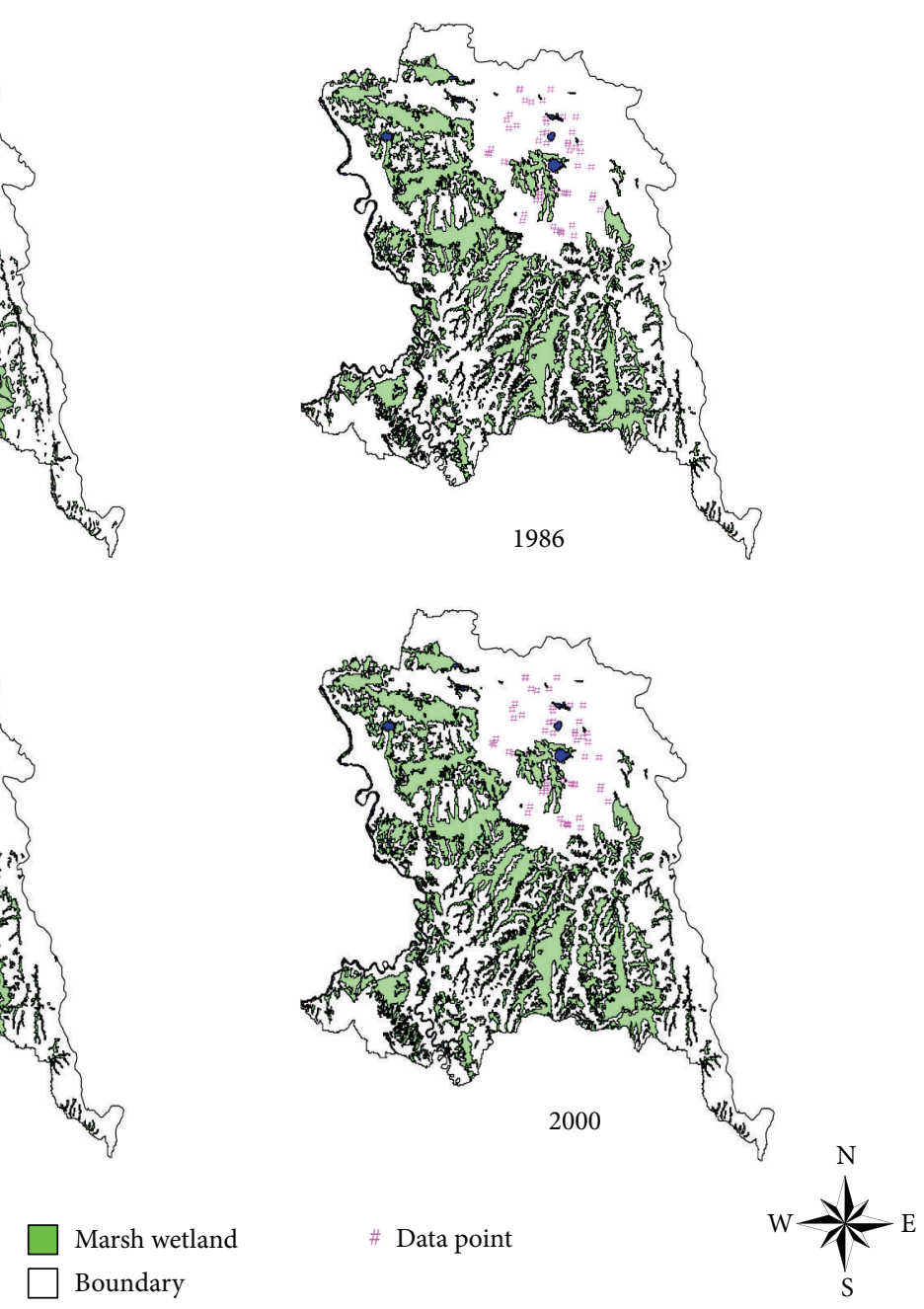

FIGURE 5: Changes in wetland landscape patterns and selected hydrological data points in degraded regions in Zoige County during the period from 1966 to 2000 .

SPSS10.0 statistical package, and correlation was considered to be significant if $P<0.05$.

\section{Results and Discussion}

\subsection{Cooling-Humidifying Effects of Alpine Wetland Landscapes}

3.1.1. Cooling Effects of Alpine Wetlands. Zoige Station in wetland area and Aba Station in nonwetland area were chosen to compare soil temperature in both stations based on the multiyear average soil temperature in top $5 \mathrm{~cm}$ soils. As shown in Figure 2, the multiyear average soil temperature was higher in Zoige Station in each month compared to Aba Station. Figure 3 showed that the annual average air temperature of Zoige Station was greatly lower than that of Aba station over the past four decades. This indicates that cooling effects of wetlands on the surrounding region were very obvious [16]. Most researchers also reported that wetlands could play significant role in reducing air temperature at least at regional scale $[17,18]$. The possible explanation was that wetlands have strong evaporative capacities which are significantly higher than those of the cultivated lands and grasslands [18], which could decrease the air temperature to some degree as the evaporation process is a heat-consuming process. Gao et al. [19] also presented that cooling effects of wetlands are closely associated with the evapotranspiration and cold radiation of wetlands, which primarily depends on the air temperature and the moisture conditions of the underlying surfaces. In the perennial flooding wetlands, the processes of warming in the daytime or cooling at night were much slower compared to seasonal flooding wetlands or meadow wetlands, for their air temperatures could be regulated by the overlying water [20]. Therefore, the moisture conditions played an important role in cooling effects of wetlands, whereas the cooling effects would be weakened or disappeared after wetland degradation, alteration or loss.

3.1.2. Humidifying Effects of Alpine Wetlands. Figure 4 illustrates the changes in the annual average relative humidity between Zoige Station and Aba Station over the past four decades. The annual average relative humidity of Zoige 


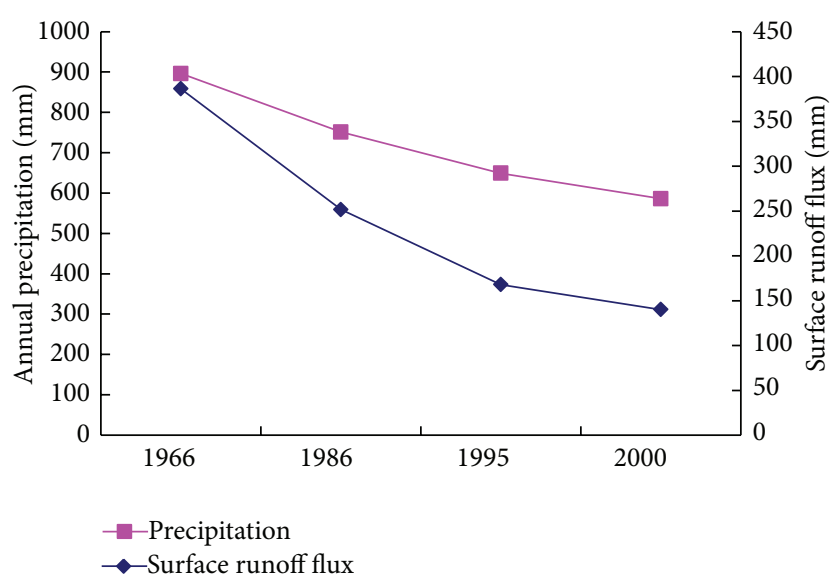

FIGURE 6: Changes in annual precipitation and surface runoff flux in the heavily degraded area in Zoige County during the period from 1966 to 2000.

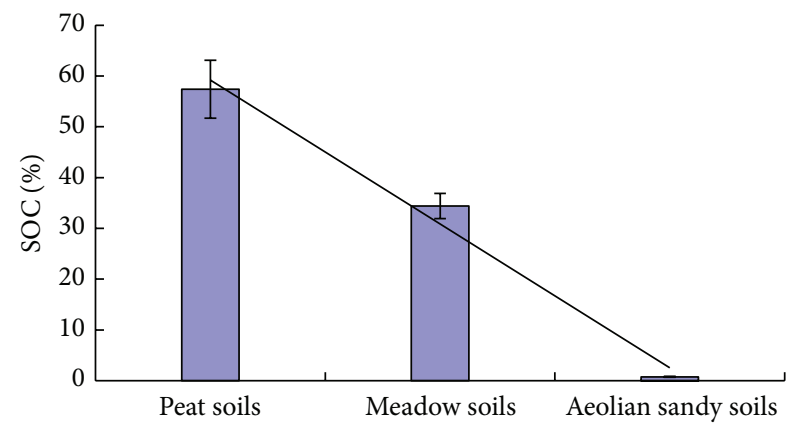

FIGURE 7: Changes in soil organic carbon contents with succession of wetland soils.

Station was higher than that of Aba Station, indicating obvious humidifying effects of alpine wetlands. This was because of higher evapotranspiration in wetlands than in nonwetlands, which can lead to higher relative humidity in wetland areas [21, 22]. Sun and Zhang [13] found that the evaporation of alpine wetlands on the Zoige Plateau was about 2 to 4 times higher than that in surrounding area, and in perennial flooding wetlands, it was about 2 times as much as that of meadows. Additionally, Sun and Zhang [13] also presented that once the relative humidity exceeds $91 \%$ to $99 \%$ in wetlands, dews would be formed, which was also one main source of the moisture.

3.1.3. Relationships between Wetland Degradation and Regional Precipitation. Wetland degradation or expansion also had a close relation with regional precipitation. Figure 5 showed the changes in wetland landscape patterns in Zoige County during the period from 1966 to 2000 based on landscape analysis [23]. There were a large number of marsh wetlands in Zoige County in 1966, but most marsh wetlands disappeared after 1986, especially in the northeast part of this county. Therefore, we selected this heavily degraded wetland region in Zoige County to analyze regional precipitation changes before and after wetland degradation.
Figure 6 shows the changes in the annual precipitation and the surface runoff fluxes in the heavily degraded area of Zoige County during the period from 1966 to 2000 . This study area exhibited the maximum annual precipitation and surface runoff flux in 1966, whereas the minimum values were observed in 2000 . Generally, both the annual precipitation and the surface runoff flux showed a decreasing tendency from 1966 to 2000. This indicates that the annual precipitation and surface runoff flux began to decrease after wetland degradation (converting to grasslands). Wu et al. presented that land use and land cover changes are one of the prime driving forces of climate change [24]. Deng et al. also concluded that land use and land cover changes have some effects on regional climate [25]. Meanwhile, the decreasing annual precipitation and surface runoff flux might further promote wetland degradation.

3.2. SOC Accumulation and Release in Alpine Plateau Wetlands. Alpine wetlands on the Zoige Plateau are dominantly composed of peatland wetlands with a huge carbon sink. It was estimated that the total peat reserve on the Zoige Plateau was approximately 14.08 million tons, accounting for about $40 \%$ of the national peat reserve in China, with carbon storage in this region of approximately 8.08 million tons [13]. Most researchers have paid much more attention to methane emissions from wetlands due to its warming effects of 25 times as much as that of $\mathrm{CO}_{2}$ [26]. It has been well known that marsh wetlands are the dominant natural sources of atmospheric methane [27]. However, lower methane emissions were found in this region due to alpine climate, and its emission flux is only about $0.02 \%$ of the amount from the largest Carex Lasiocarpa freshwater marsh in Northeast China [28].

Plant residual roots are the main source of soil organic carbon in alpine wetlands on the Zoige Plateau. Soil organic matter would keep accumulating due to slower decomposition under lower air temperature and higher humidity. It was estimated that the peat was accumulated at the rate of $0.38 \mathrm{~mm} \mathrm{a}^{-1}$ in this region. However, wetland degradation or loss due to anthropogenic activities such as digging trenches and drainage would lead to a large amount of carbon loss through $\mathrm{CO}_{2}$ emission due to elevated decomposition rate of soil organic matter [29]. As shown in Figure 7, SOC storage would decline linearly and be converted to carbon source from carbon sink for alpine wetlands of this region once the peat soils were converted to meadow soils or Aeolian sandy soils due to anthropogenic activities and natural conditions. However, if these degraded wetlands were restored, SOC storage in these alpine wetlands will be greatly increased.

\subsection{Relationships between Alpine Wetland Landscape Areas} and Regional Meteorological Factors. Table 1 showed the correlation matrix between wetland landscape areas (A) on the Zoige plateau covering five counties (i.e., Zoige, Hongyuan, Aba, Maqu, and Luqu) in four time periods (i.e., 1966, 1986, 1995, and 2000) [10] and these selected meteorological factors. We put together all the data on the wetland landscape areas and the corresponding meteorological factors of five 


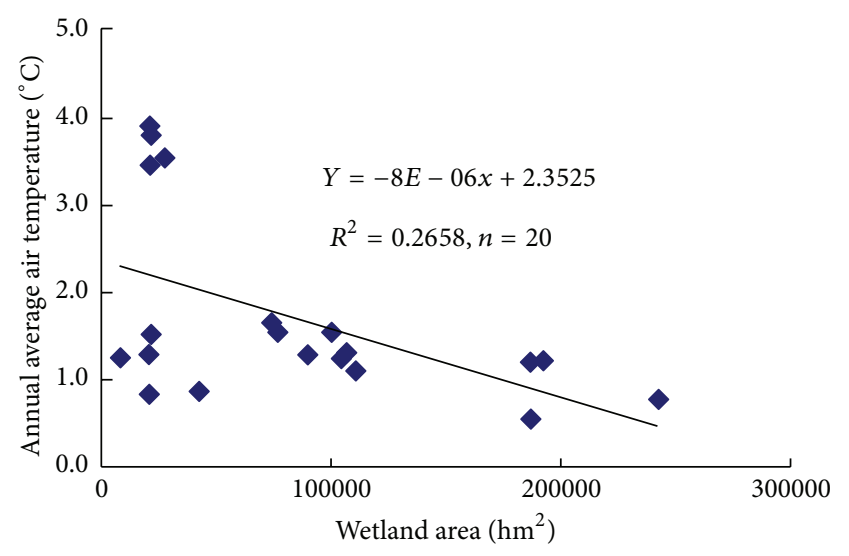

(a)

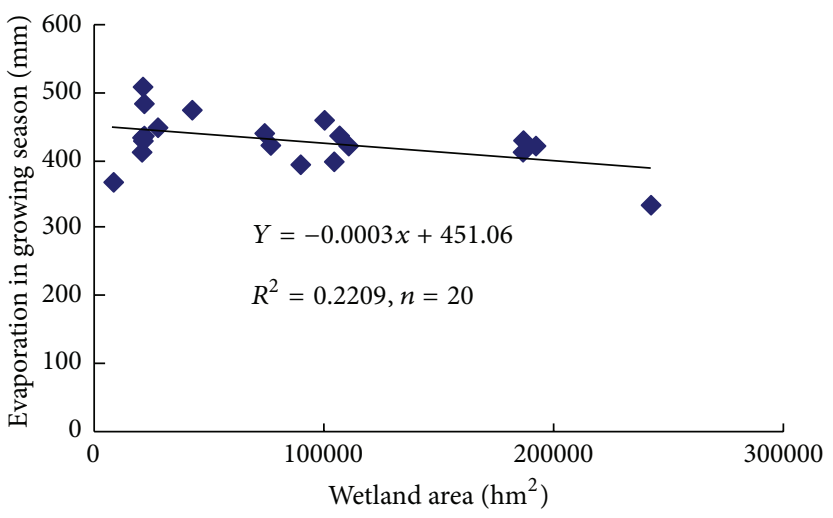

(b)

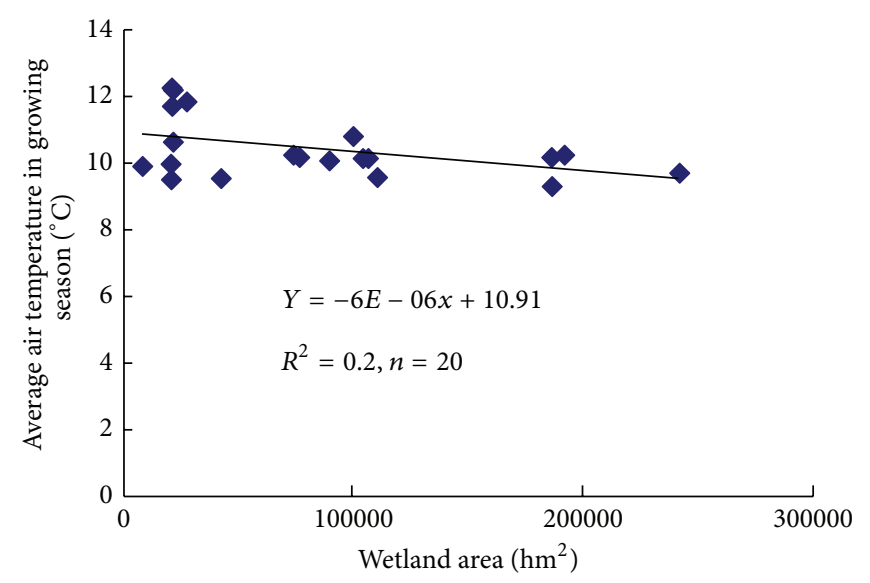

(c)

FIGURE 8: Relationships between wetland landscape areas (A) and the annual average air temperature (AAAT), the average air temperate in growing seasons (AATGS), and the evaporation in growing seasons (EGS).

counties to carry out the statistical analysis. Correlation analysis showed that wetland landscape area was significantly negatively correlated with the annual average air temperature (AAAT), the average air temperature in growing seasons (AATGS), and the evaporation in growing seasons (EGS) $(P<0.05$; Table 1). However, no significant correlation was observed among $\mathrm{A}$ and other selected meteorological factors such as annual precipitation (AP), annual evaporation $(\mathrm{AE})$, annual average relative humidity (AARH), and the average relative humidity in growing season (ARHGS) and precipitation in growing seasons (PGS) $(P>0.05$; Table 1$)$. Regression analysis also exhibited that AAAT, AATGS, and EGS decreased gradually with increasing wetland areas in growing seasons (Figure 8). This indicates that AAAT, AATGS, and EGS in growing seasons would decrease with increasing wetland landscape areas due to the coolinghumidifying effects of wetlands. Meanwhile, the above results of statistical analysis imply that the wetland landscape areas are related to the surrounding regional climate (e.g., air temperature, $P<0.05$; Table 1 ), especially in growing seasons (e.g., AATGS and EGS) because the thawing period lasts from May to September and the freezing period lasts from October to the next April in these alpine wetlands. Moreover, the precipitation and evaporation mainly concentrated in the growing seasons in this region.

\section{Conclusions}

Alpine wetlands have obvious cooling and humidifying effects and play an important role in regulating regional climate, especially in growing seasons. The annual average temperature and the average temperature and the evaporation in the growing seasons will be lower in those areas with large-area wetlands. Wetlands will be converted to carbon sources from carbon sinks after serious wetland degradation, alteration, or loss. Therefore, it is very necessary to protect and restore degraded alpine wetlands in the alpine regions or mountain regions to improve the cooling and humidifying effects of wetlands, which will contribute to increasing water storage and carbon storage, and thus alleviating global warming.

\section{Acknowledgments}

This work was financially supported by National Basic Research Program (no. 2010CB951102), National Natural 
Science Foundation (nos. 51179006 and 51379012), Program for New Century Excellent Talents in University (NECT10-0235), and the Fok Ying-Tong Education Foundation for Young Teachers in the Higher Education Institutions of China (no. 132009).

\section{References}

[1] X. M. Meng, "Wetlands and global environmental change," Acta Geographica Sinica, vol. 19, no. 5, pp. 385-391, 1999.

[2] W. J. Mitsch and J. G. Gosselink, "Changes in atmospheric constituents and in radioactive forcing," http://www.ipcc.ch/pdf/ assessment-report/ar4/wg1/ar4-wg1-chapter2.pdf.

[3] M. K. Cao and K. R. Li, "Perspective on terrestrial ecosystemclimate interaction," Advance in Earth Sciences, vol. 15, no. 4, pp. 446-451, 2000.

[4] W. J. Mitsch and X. Wu, "Wetlands and global change," Advances in Soil Science, pp. 205-230, 1995.

[5] J. L. Bubier, G. Bhatia, T. R. Moore, N. T. Roulet, and P. M. Lafleur, "Spatial and temporal variability in growing season net ecosystem carbon dioxide exchange at a large peatland in Ontario, Canada," Ecosystems, vol. 6, no. 4, pp. 353-367, 2003.

[6] P. M. Lafleur, N. T. Roulet, J. L. Bubier, S. Frolking, and T. R. Moore, "Interannual variability in the peatland-atmosphere carbon dioxide exchange at an ombrotrophic bog," Global Biogeochemical Cycles, vol. 7, no. 5, pp. 1-5, 2003.

[7] D. S. Schimel, B. H. Braswell, E. A. Holland et al., "Climatic, edaphic, and biotic controls over storage and turnover of carbon in soils," Global Biogeochemical Cycles, vol. 8, no. 3, pp. 279-293, 1994.

[8] E. Gorham, "Northern peatlands: role in the carbon cycle and probable responses to climatic warming," Ecological Applications, vol. 1, no. 2, pp. 182-195, 1991.

[9] K. L. Chen, X. H. Zhang, and Y. Lv, "Climate change and wetland," Wetland Science, vol. 1, no. 1, pp. 73-77, 2003.

[10] J. H. Bai, Q. Q. Lu, J. J. Wang et al., "Landscape pattern evolution processes of alpine wetlands and their driving factors in the Zoige Plateau of China," Journal of Mountain Science, vol. 10, no. 1, pp. 54-67, 2013.

[11] J. H. Bai, H. Ouyang, B. S. Cui et al., "Changes in landscape pattern of alpine wetlands on the Zoige Plateau in the past four decades," Acta Ecologica Sinica, vol. 28, no. 5, pp. 2245-2252, 2008.

[12] H. Chen, N. Wu, Y. F. Wang et al., "Inter-annual variations of methane emission from an open fen on the Qinghai-Tibetan Plateau: a three-year study," Plos ONE, vol. 8, no. 1, Article ID e53878, 2013.

[13] S. G. Sun and Z. W. Zhang, "Old channels of the Huanghe River on Ruoergai Plateau and its palaeogeographic significance," Scientia Geographica Sinica, vol. 7, no. 3, pp. 266-272, 1987.

[14] J. H. Bai, Spatio-temropal evolution process of alpine wetlands and their effects on regional climate in Zoige Pleatu [Postdocotoral dissertation], Insitute of Geographical Sciences and Natural Resources Research, Chinese Academy of Sciences, 2005.

[15] A. Walkley and I. A. Black IA, "An examination of the Degtjareff method for determining soil organic matter and a proposed modification of the chromic acid titration method," Soil Science, vol. 37, pp. 29-38, 1934.
[16] Y. Zhang, X. G. Lv, and J. Ni, "Cold-humid ecological effects of the Sanjiang plain," Ecology and Environment, vol. 13, no. 1, pp. 37-39, 2004.

[17] X. H. Ma, "Lakeshore swamps of Bositeng lake in the Xinjiang autonomous region," Oceanologia et Limnologia Sinica, vol. 20, no. 6, pp. 554-563, 1989.

[18] G. Q. Chen, H. G. Niu, and X. G. Lv, Swamp Study of Sanjiang Plain, Science Press, Beijing, China, 1996.

[19] J. Q. Gao, X. G. Lv, and H. Y. Liu, "Cold-humid effect of wetlands," Rural Ecoenvironment, vol. 19, no. 1, pp. 18-21, 2003.

[20] X. Chai, H. Q. Lang, S. Z. Jin et al., Zoige Plateau Mire, Science Press, Beijing, China, 1965.

[21] X. L. Gong, Y. Y. Wang, X. Nie, and X. M. Yin, "Differences in air temperature and relative humidity between a marsh wetland and its surrounding dry farmlands," Journal of NorthEast Forestry University, vol. 39, no. 11, pp. 93-96, 2011.

[22] L.-M. Rebelo, G. B. Senay, and M. P. McCartney, "Flood pulsing in the Sudd wetland: analysis of seasonal variations in inundation and evaporation in South Sudan," Earth Interactions, vol. 16, no. 1, pp. 1-19, 2012.

[23] X. Deng, Q. Jiang, J. Zhan, S. He, and Y. Lin, "Simulation on the dynamics of forest area changes in Northeast China," Journal of Geographical Sciences, vol. 20, no. 4, pp. 495-509, 2010.

[24] F. Wu, J. Y. Zhan, H. M. Yan, C. C. Shi, and J. Huang, "Land cover mapping based on multisource spatial data mining approach for climate simulation: a case study in the farming-pastoral ecotone of North China," Advance in Meteorology, vol. 2013, Article ID 520803, 12 pages, 2013.

[25] X. Z. Deng, C. H. Zhao, and H. M. Yan, "Systematic modeling of impacts of land use and land cover changes on regional climate: a review," Advance in Meteorology, vol. 2013, Article ID 317678, 11 pages, 2013.

[26] G. Raga, M. Schulz, and R. van Dorland, "Changes in atmospheric constituents and in radiative forcing," in Climate Change 2007: the Physical Science Basis. Contribution of Working Group I To the Fourth Assessment Report of the Intergovernmental Panel on Climate Change, S. Solomon, D. Qin, M. Manning et al., Eds., Cambridge University Press, New York, NY, USA, 2007.

[27] X. S. Dai, G. Y. Shi, and M. Dong, Global Warming, China Meteorological Press, Beijing, China, 1998.

[28] D. X. Wang, X. G. Lv, W. X. Ding et al., "Methane emission from marshes in Zoige Plateau," Advance in Earth Sciences, vol. 17, no. 6, pp. 877-880, 2002.

[29] J. H. Bai, H. Ouyang, R. Xiao et al., "Spatial variability of soil carbon, nitrogen, and phosphorus content and storage in an alpine wetland in the Qinghai-Tibet Plateau, China," Australian Journal of Soil Research, vol. 48, no. 8, pp. 730-736, 2010. 

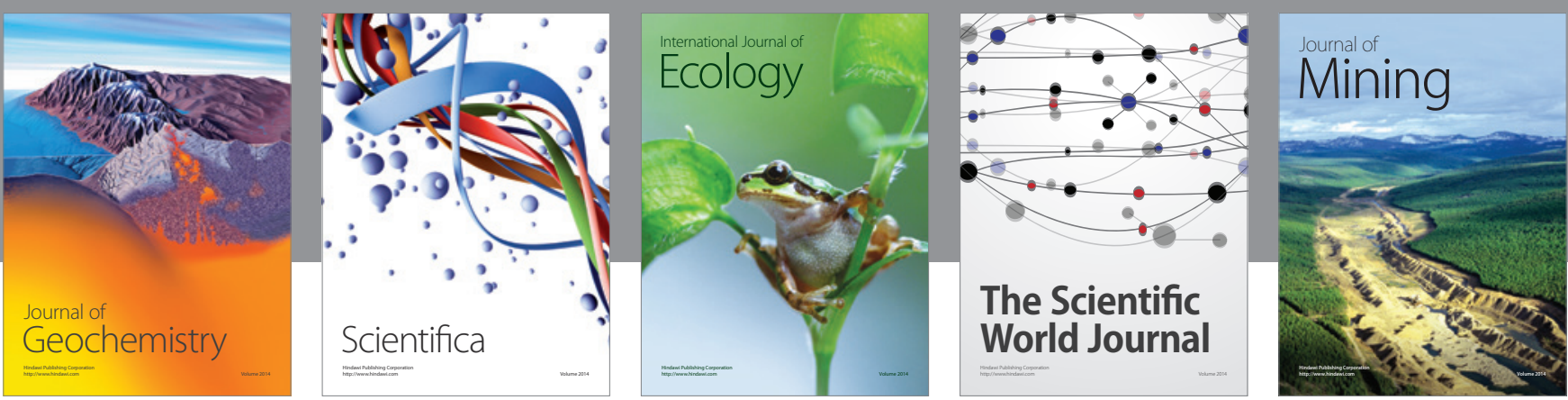

The Scientific World Journal
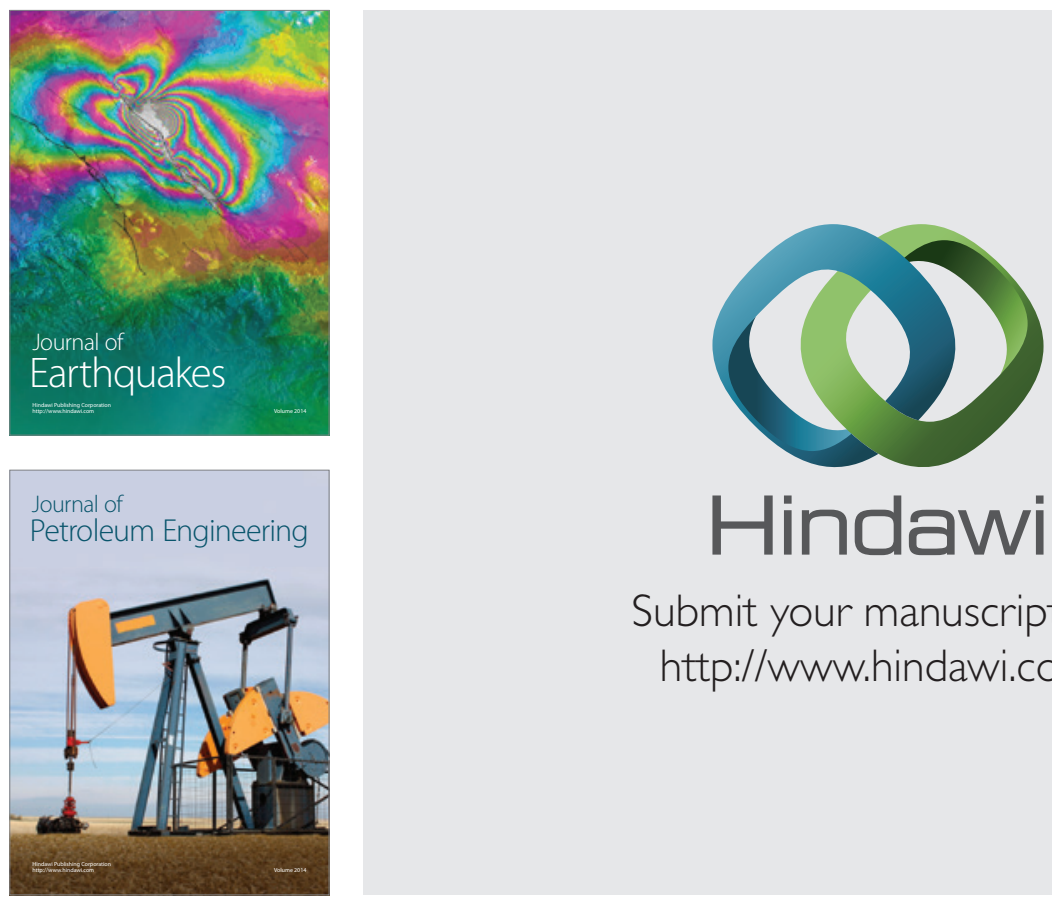

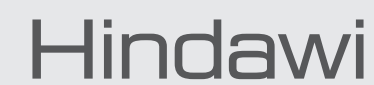

Submit your manuscripts at

http://www.hindawi.com
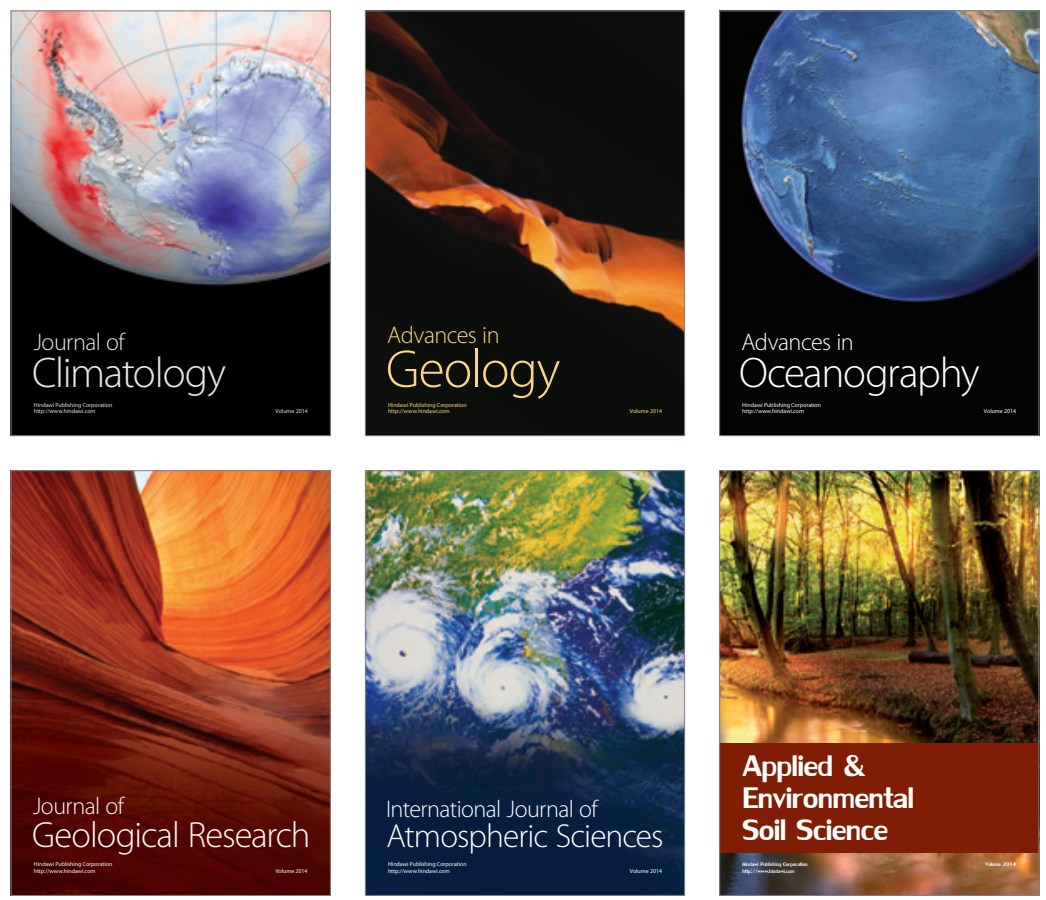
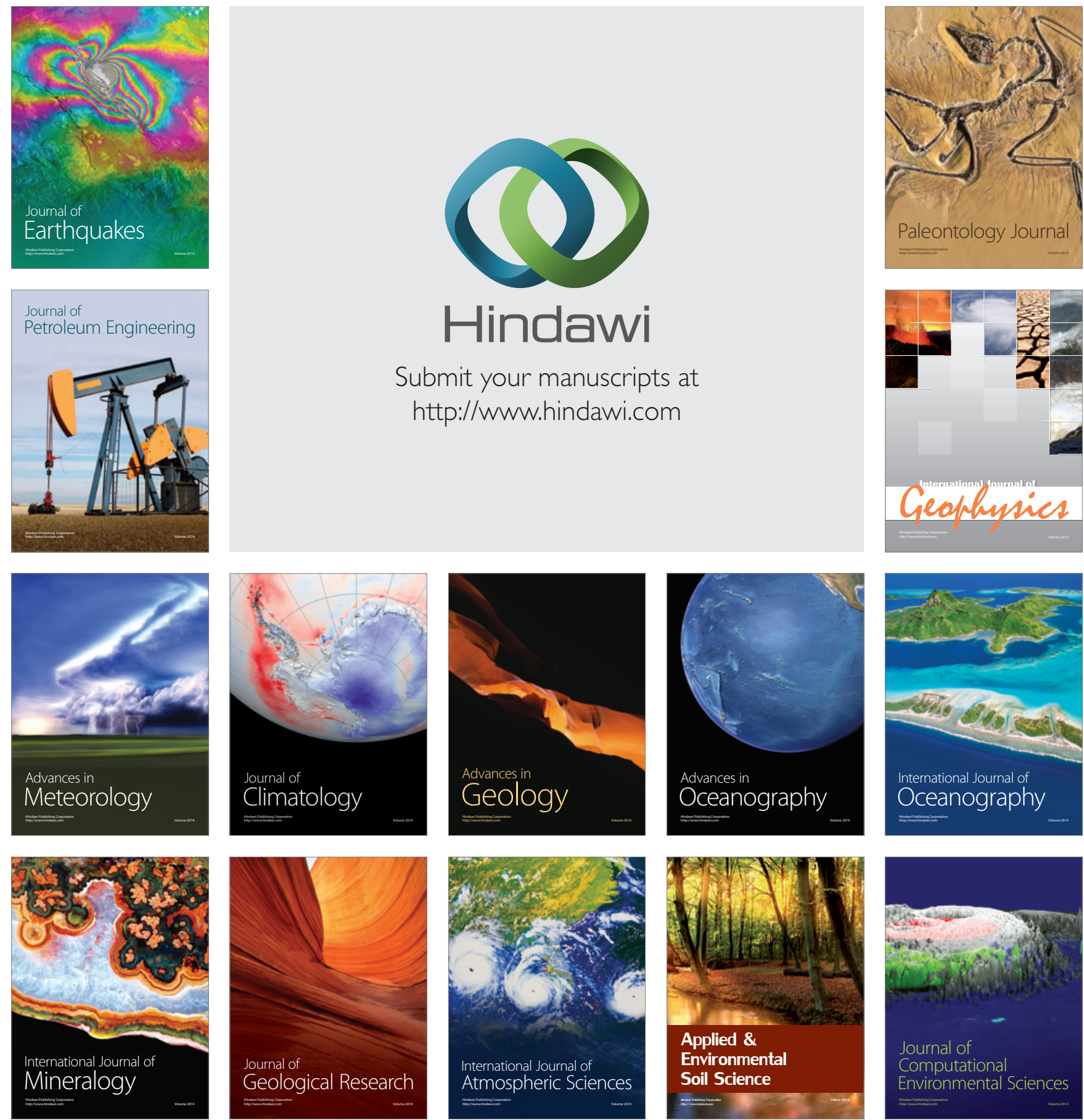